\title{
Frequency of Renal Dysfunction and its effects on outcomes after open heart surgery
}

\author{
Taimur Asif Ali ${ }^{1}$, Khuzaima Tariq ${ }^{2}$, \\ Areej Salim ${ }^{3}$, Saulat Fatimi ${ }^{4}$
}

\begin{abstract}
Objectives: In this study we determined the frequency of renal dysfunction and its outcomes in terms of morbidity and mortality in patients who underwent open heart surgery at the Aga Khan University Hospital, Karachi, Pakistan.

Methods: A total of 175 patients aged between 15-80 years having open heart Surgery(OHS) were included. Preoperative and postoperative serum creatinine $(\mathrm{SCr})$ was noted and the glomerular filtration rate (GFR) calculated by Cockcroft-Gault equation. Their hospital course was charted and followed-up for 30-day.

Results: The mean age and mean BMI were $58.1 \pm 12.6$ years and $26.4 \pm 4.3 \mathrm{~kg} / \mathrm{m} 2$ respectively. Females were $18.3 \%$, out of which $51.4 \%$ hypertensive, $46.9 \%$ diabetics, $45.1 \%$ had dyslipidemia, $2.9 \%$ had preoperative renal dysfunction and $40 \%$ had moderate ejection fraction. On follow up, 30.3\% developed postoperative renal dysfunction within 30-days after OHS with mean $\mathrm{SCr}$ and GFR as $1.6 \pm 0.7$ and $56.9 \pm 24.5$, respectively. In RD group more patients showed positive outcomes i.e. prolonged inotropic requirement $(75.5 \% \mathrm{vs}$. $18 \%$, $p$-value $<0.005)$, diuretic infusion usage $(47.2 \%$ vs. $3.3 \%$, p-value $<0.005)$, dialysis/renal replacement therapy $(17 \%$ vs. $0 \%, p$-value $<0.005)$, requirement for prolonged ventilation $(35.8 \%$ vs. $6.6 \%$, $p$-value $<0.005)$, prolonged ICU and hospital stay $(15.4 \%$ vs. $1.6 \%$, p-value $<0.005$ and $41.5 \%$ vs. $17.2 \%$, p-value $<0.005)$, sepsis $(20.8 \%$ vs. $1.6 \%$, $p$-value $<0.005)$ and death $(9.4 \%$ vs. $2.5 \%$, p-value 0.05$)$.

Conclusion: Timely recognition of renal dysfunction, early renal replacement therapy, diuretics or dialysis and proper nutritional and inotropic support to maintain adequate hemostasis shows survival benefits.
\end{abstract}

KEYWORDS: Renal dysfunction, Open heart surgery, Serum creatinine, Glomerular filtration rate, Cardiopulmonary bypass.

doi: https://doi.org/10.12669/pjms.37.7.3865

How to cite this:

Ali TA, Tariq K, Salim A, Fatimi S. Frequency of Renal Dysfunction and its effects on outcomes after open heart surgery. Pak J Med Sci. 2021;37(7):1979-1983. doi: https://doi.org/10.12669/pjms.37.7.3865

This is an Open Access article distributed under the terms of the Creative Commons Attribution License (http://creativecommons.org/licenses/by/3.0), which permits unrestricted use, distribution, and reproduction in any medium, provided the original work is properly cited.

1. Dr. Taimur Asif Ali, FCPS

2. Dr. Khuzaima Tariq, FCPS.

3. Dr. Areej Salim, MBBS

4. Dr. Saulat Fatimi, MD.

1,2: Department of Cardiac Surgery,

National Institute of Cardiovascular Diseases, Karachi, Pakistan.

3,4: Agha Khan University Hospital, Karachi, Pakistan.

Correspondence:

Dr. Khuzaima Tariq, FCPS.

Department of Cardiac Surgery,

National Institute of Cardiovascular Diseases,

Karachi, Pakistan.

Address: H.No: 492 DOHS Phase 1,

Malir Cantt, Karachi, Pakistan.

E-mail: khutarek@gmail.com

* Received for Publication:

* Revision Received:

* Revision Accepted:

Pak J Med Sci November - December 2021
November 2, 2020

May 29, 2021

June 12, 2021

\section{INTRODUCTION}

Acute kidney injury resulting in renal dysfunction (RD) occurs in up to $30 \%$ of all patients after open heart surgery and $1 \%$ of those may require dialysis. ${ }^{1,2}$ The recent studies show incidence of post-surgery acute kidney injury varies from 5 to $42 \%{ }^{3,4}$ Multiple causative factors may contribute to perioperative acute renal dysfunction, they may be categorized as pre-renal (reduced renal perfusion), renal (intrinsic renal insults), or post-renal (obstructive uropathy). It may occur as a result of renal ischemic injury, exotoxins (antibiotics, anesthetic agent, contrast media, and diuretics), endotoxins (myoglobin), and pre-existing renal impairment. 
The institution of cardiopulmonary bypass (CPB) during open heart surgery ensues a systemic inflammatory response marked by increased membrane permeability and a transient capillary leak, it can pre-empt normal reflexes and chemoreceptor controls of the circulation by initiating coagulation cascades, circulating cell-signaling proteins, inflammatory cytokines, and entails microembolic phenomena leading to organ malperfusion. Extravasation of fluids into the interstitial space may contribute to cerebral edema, hepatic congestion, splanchnic congestion, and renal dysfunction. Either reversible or irreversible cell injury may occur. A prolonged bypass time ( $>4$ hours) may cause hemoglobinuria, leading to impaired renal tubular function. The patients undergoing valvular or combined procedures are at two to three-fold risk of developing postoperative renal dysfunction, owing to prolonged CPB time. ${ }^{5,6}$ Previous literature has identified many risk factors associated with acute kidney injury following open heart surgery such as female gender, elevated serum creatinine and decreased GFR, perioperative hemoglobin area under the curve, ${ }^{7}$ use of Angiotensinconverting enzyme inhibitors, ${ }^{8}$ other nephrotoxic medications or intravenous contrast, ${ }^{9} \mathrm{LVEF}<35 \%$, emergent surgery, shock, length of CPB and Aortic cross clamp time, co-morbidities like chronic obstructive pulmonary disease (COPD), diabetes mellitus, peripheral vascular disease, pre-existing renal insufficiency, congestive heart failure. ${ }^{10}$

Renal dysfunction is graded into mild, moderate or severe dysfunction measured by the level of serum creatinine (SCr) and/ or estimated glomerular filtration rate (GFR) ${ }^{11}$ Its moderate to severe level $\left(\mathrm{SCr}>2.2 \mathrm{mg} / \mathrm{dL}\right.$ or $\mathrm{GFR}<30 \mathrm{ml} / \mathrm{min} / 1.73 \mathrm{~m}^{2}$ ) or end-stage renal disease are found to be most devastating among cardiac surgery patients. There is increased risk of sepsis, prolonged ventilation and prolong ICU stay and re-admission. ${ }^{12}$ In the present study we intend to find out the effect of postoperative renal dysfunction on patients' outcomes.

\section{METHODS}

After taking permission from the competent authority and attaining an exemption from the Ethics Review Committee (ERC) (Ref\# 2205-SurERC-12 dated July 30, 2020), this study was undertaken at Department of Cardiothoracic Surgery of Aga Khan University Hospital, Karachi, Pakistan. Patients aged between 15-80 years with left ventricular ejection fraction (LVEF) $>30 \%$ who underwent $\mathrm{OHS}$ utilizing cardiopulmonary bypass with preoperative SCr upto $1.5 \mathrm{mg} / \mathrm{dL}$ were deemed fit for inclusion. Patients below 15 and above 80 years with preoperative $\mathrm{SCr}>1.5 \mathrm{mg} / \mathrm{dl}$ or already on dialysis, candidates of emergency surgery, offpump surgery with LVEF $<30 \%$ were excluded. Duration of the study spanned over six months.

Initiated with an informed consent, the patients were recruited on the basis of eligibility criteria of preoperative serum creatinine $(\mathrm{SCr})<1.5 \mathrm{mg} / \mathrm{dl}$ measured from laboratory reports and calculation of GFR by the Cockcroft-Gault equation using age, weight and sex; [formula $=(140$-age) $x$ Weight in $\mathrm{kg} \times(0.85$ if female) / $72 \times \mathrm{Cr})]$. Baseline patient characteristics were inquired verbally through a structured questionnaire. Strict confidentiality of the study subjects and information was maintained.

Two samples ofSCrwerechosen, one preoperative and second postoperative highest $\mathrm{SCr}$ value. If any of the post-operative $S C r$ readings were found to be positive (i.e., SCr $>1.5$; GFR $30-89 \mathrm{ml} / \mathrm{min} / 1.73$ $\mathrm{m}^{2}$ ) then the patient has been considered as having renal dysfunction. They were all followed for 30 days in the hospital or at clinic if discharged, and assessed for either the presence or absence of adverse outcomes i.e, death, length of hospital stay after surgery $\geq 8$-days, length of ICU stay $>6$-days, ventilatory support requirement $\geq 24$-hours, sepsis, renal therapy with diuretic infusions $\geq 24$-hours, dialysis or continuous renal replacement therapy (CRRT) for anuric renal impairment and sepsis (seen by positive microbial growth either in blood, urine, tracheal or wound cultures). All patients have been operated by a team of consultant cardiac surgeons having post-fellowship experience of about 5-years in the relevant field.

\section{RESULTS}

The mean age of our population was $58.1 \pm 12.6$ years with mean BMI of $26.4 \pm 4.3 \mathrm{~kg} / \mathrm{m}^{2}$ and $81.7 \%$ were males as shown in Table-I. The perioperative risk factors of our study population showed $51.4 \%$ hypertensive and presence of dyslipidemia in $45.1 \%$. Similarly, the risk factors of DM and smoking were present in $46.9 \%$ and $33.1 \%$ respectively. Moderate to severe LV dysfunction in a preoperative state also predisposes a patient to renal dysfunction. $23.4 \%$ of our study population had a moderate LV dysfunction (i.e. 30-40\%).

The preoperative normal functioning of the kidneys is represented by the mean preoperative creatinine at the day of admission which was $1.1 \pm 0.2 \mathrm{mg} /$ $\mathrm{dL}$. It increased to a mean of $1.6 \pm 0.7 \mathrm{mg} / \mathrm{dL}$ postoperatively. Similarly, the glomerular filtration rate 
Table-I: Baseline data and demographic characteristics.

\begin{tabular}{lc}
\hline Characteristics & $N=175$ \\
\hline Age & $58.1 \pm 12.6$ \\
Body mass index (BMI) & $26.4 \pm 4.3$ \\
Gender & \\
Female & $32(18.3 \%)$ \\
Male & $143(81.7 \%)$ \\
Risk profile & \\
Smoking & $58(33.1 \%)$ \\
Diabetes mellitus & $82(46.9 \%)$ \\
Hypertension & $90(51.4 \%)$ \\
Dyslipidemia & $79(45.1 \%)$ \\
HoRF & $5(2.9 \%)$ \\
Ejection fraction (EF) & \\
$30-40 \%$ & $41(23.4 \%)$ \\
$41-60 \%$ & $70(40.0 \%)$ \\
$\geq 60 \%$ & $62(35.4 \%)$ \\
Pre-op Creatinne & $1.1 \pm 0.2$ \\
Pre-op GFR & $78.7 \pm 29.3$ \\
Post-op Creatinine & $1.6 \pm 0.7$ \\
Post-op GFR & $56.9 \pm 24.5$ \\
\hline
\end{tabular}

(GFR), as a second predictor and tool, was measured by Cockcroft-Gault equation was $78.7 \pm 29.3$ $\mathrm{ml} / \mathrm{min} / 1.73 \mathrm{~m}^{2}$ preoperatively and showed reduction postoperatively to $56.9 \pm 24.5 \mathrm{ml} / \mathrm{min} / 1.73 \mathrm{~m}^{2}$.

The outcomes within 30-days of open heart surgery is shown in Table-II. Occurrence of RD was seen in $30.3 \%$ of patients. There were more patients showing positive outcomes in RD group as compared to non-RD group i.e. Prolonged inotropic requirement $(75.5 \%$ vs. $18 \%$, p-value $<0.005)$, dialysis / RRT requirement was found in $5.1 \%$ and the mortality was $4.6 \%$. The requirement of either only continuous diuretic infusions or the institution of dialysis or renal replacement therapy was seen in $16.6 \%$ and $5.1 \%$ respectively. Patient to be retained either in the ICU for a period of greater than 6-days or in the hospital for $>8$-days marking prolonged

Table-II: Post-operative 30 days outcomes.

\begin{tabular}{lc}
\hline Outcomes & $N=175$ \\
\hline Renal dysfunction & $53(30.3 \%)$ \\
Inotrope use ( $\geq 24$ hours) & $62(35.4 \%)$ \\
Diuretic infusion use & $29(16.6 \%)$ \\
Dialysis / RRT & $9(5.1 \%)$ \\
Positive pressure ventilation $(\geq 24 \mathrm{hr})$ & $27(15.4 \%)$ \\
ICU stay & \\
$\leq 6$ days & $164(93.7 \%)$ \\
$\geq 6$ days & $11(6.3 \%)$ \\
Hospital stay & \\
$\leq 8$ days & $132(75.4 \%)$ \\
$\geq 8$ days & $43(24.6 \%)$ \\
Sepsis & $13(7.4 \%)$ \\
Death & $8(4.6 \%)$ \\
\hline
\end{tabular}

stay was seen in $6.3 \%$ and $24.6 \%$ respectively, in the whole group. Sepsis was reported in $7.4 \%$ patients and death in $4.6 \%$ patients.

We also analyzed the association of occurrence of RD with multiple risk factors or co-morbidities. Table-III. In those patients who had postoperative $\mathrm{RD}$, greater than $50 \%$ were diabetics. The majority $71.7 \%$ had history of hypertension, $58.5 \%$ were dyslipidemics and $41.5 \%$ had history of smoking. Patients having mild to moderate LV dysfunction were seen to be more predisposed to $\mathrm{RD}$ as it occurred in more than $82 \%$ as compared to patients having a normal LV ejection fraction of $>60 \%$.

With analysis of the comorbidities and adverse outcomes, it was seen that variables of preoperative presence of hypertension, dyslipidemia and preoperative LVEF were also significant $(p<0.05)$. The perioperative variables of inotropic use $>$ 24-hrs and the requirement of positive pressure ventilation for $>24$-hrs was also seen statistically significant $(p<0.05$. Due to the development of RD,

Table-III: Clinical characteristics and analysis of post-operative 30 days outcomes in renal dysfunction and non-dysfunction groups.

\begin{tabular}{|c|c|c|c|}
\hline \multirow[t]{2}{*}{ Characteristics } & \multicolumn{2}{|c|}{ Renal Dysfunction } & \multirow[t]{2}{*}{ P-value } \\
\hline & Yes & No & \\
\hline Total (N) & 53 & 122 & - \\
\hline \multicolumn{4}{|l|}{ Gender } \\
\hline Male & $44(83 \%)$ & $99(81.1 \%)$ & 0.769 \\
\hline Female & $9(17 \%)$ & $23(18.9 \%)$ & \\
\hline \multicolumn{4}{|l|}{ Risk factors } \\
\hline Diabetes & $28(52.8 \%)$ & $54(44.3 \%)$ & 0.297 \\
\hline Hypertension & $38(71.7 \%)$ & $52(42.6 \%)$ & $<0.005$ \\
\hline Dyslipidemia & $31(58.5 \%)$ & $48(39.3 \%)$ & 0.019 \\
\hline Smoking & $22(41.5 \%)$ & $36(29.5 \%)$ & 0.121 \\
\hline \multicolumn{4}{|l|}{ Ejection fraction } \\
\hline $30-40 \%$ & $17(32.1 \%)$ & $24(19.7 \%)$ & $<0.005$ \\
\hline $41-60 \%$ & $32(60.4 \%)$ & $38(31.1 \%)$ & \\
\hline$>60 \%$ & $4(7.5 \%)$ & $60(49.2 \%)$ & \\
\hline Inotrope use $>24$-hrs & $40(75.5 \%)$ & $22(18 \%)$ & $<0.005$ \\
\hline \multicolumn{3}{|c|}{ Diuretic infusion use } & $<0.005$ \\
\hline \multicolumn{4}{|c|}{ Renal replacement therapy } \\
\hline $\begin{array}{l}\text { Positive pressure } \\
\text { ventilation }>24-h r s\end{array}$ & $19(35.8 \%)$ & $8(6.6 \%)$ & $<0.005$ \\
\hline \multicolumn{4}{|l|}{ ICU stay } \\
\hline$>6$-days & $8(15.1 \%)$ & $2(1.6 \%)$ & 0.001 \\
\hline$<6$-days & $45(84.9 \%)$ & $120(98.4 \%)$ & \\
\hline \multicolumn{4}{|l|}{ Length of hospital stay } \\
\hline$>8$-day & $22(41.5 \%)$ & $21(17.2 \%)$ & 0.001 \\
\hline$<8$-days & $31(58.5 \%)$ & $101(82.8 \%)$ & \\
\hline Sepsis & $11(20.8 \%)$ & $2(1.6 \%)$ & $<0.005$ \\
\hline Death & $5(9.4 \%)$ & $3(2.5 \%)$ & 0.05 \\
\hline
\end{tabular}


the requirement of use of diuretics infusions and further requirement of dialysis or RRT was seen to be statistically significant $(p<0.05)$. All these lead to a statistically significant $(p<0.05)$ prolong ICU and hospital stay as well as development of sepsis leading to death.

\section{DISCUSSION}

This study showed that patients undergoing open heart surgical procedures at our setup are at increased risk for developing postoperative RD. There is complex interplay of number of factors which might explain its association with open heart surgery importantly preoperative health of kidneys, associated comorbidities, effects of CPB, myocardial revascularization, reperfusion injury, fluid overload, retention of uremic compounds, acidosis, electrolyte imbalance, increased risk for sepsis and anemia etc. The National Kidney Foundation in USA had formulated guideline for the optimization of patients who have preoperative dysfunction and divided it into mild, moderate or severe categories. To properly assess and compare the incidence and outcomes of Acute Kidney Injury worldwide, the Acute Dialysis Quality Initiative Group proposed a standard classification termed "RIFLE" in 2004, which stands for the acronym "Risk, Injury, Failure, Loss of function and End stage kidney disease", and is based on two criteria: serum creatinine levels (SCr) and urine output. ${ }^{13}$ henceforth, the term Acute renal failure was officially replaced by Acute Kidney Injury(AKI). ${ }^{14}$ The currently used criteria, were published in 2012 by the Kidney Disease Improving Global Outcome (KDIGO) workgroup which contains guidelines on risk assessment, evaluation, prevention and treatment. Definition and staging of AKI are based on the Risk, Injury, Failure, Loss, End-stage renal disease(RIFLE) and Acute Kidney Injury Network (AKIN) criteria. ${ }^{15}$ It is interestingly noted that even a small rise in creatinine is associated with a higher mortality. The degree of rise in creatinine perioperatively closely correlates with increased mortality. A preoperative creatinine $>1.5 \mathrm{mg} / \mathrm{dL}$ entails a cumulative mortality risk ranging from $5-30 \% .{ }^{16}$ The estimated mortality risk is about 5\% for patients with a creatinine of $1.5-2.5 \mathrm{mg} / \mathrm{dL}$, and approximately $15-30 \%$ in non-dialysis-dependent patients with a creatinine $>2.5 \mathrm{mg} / \mathrm{dL}$. Lassnigg et $a l^{17}$ observed that in patients showing a rise in serum creatinine $>0.5 \mathrm{mg} / \mathrm{dL}$ above the baseline had a 2.77 -fold increase in mortality and those who had even more than a greater than $0.5 \mathrm{mg} / \mathrm{dL}$ from baseline had an increased mortality of 18.64 -folds in early postoperative period.

Headley et $a l^{18}$ studied the effects of CPB on patients undergoing different types of open heart surgery. Their series showed a mortality rate which ranged from $1.3 \%$ in simple procedures to as high as $11 \%$ for complex procedures in association with $11.3 \%$ development of renal dysfunction. Simon et $a l^{19}$ showed that the length of ICU and hospital stay and requirement of mechanical ventilation was very much influenced by the health of the kidneys. A relationship of developing RD by association of gender, age and BMI was also quite comparable.

The management of established postoperative renal dysfunction, so far has been supportive, including optimization of hemodynamic status, adequate hydration, correction of metabolic derangements, correction of acid-base balance, avoidance of nephrotoxic drugs and tight glycemic control. The basic treatment regime remains the same stressing upon preventive measures such as limiting nephrotoxic medication and iodinated contrast agents with optimizing volume status. ${ }^{20}$ recent areas of research including remote ischemic preconditioning and pharmacological interventions have showed limited efficacy in preventing renal dysfunction. The multicenter double-blind placebo-controlled clinical trial STOP-AKI trial ${ }^{21}$ has been recently published evaluating the safety and efficacy of human recombinant alkaline phosphatase as anti-inflammatory treatment for patients with septic AKI. This trial and many other studies failed to show promising results in improving kidney function. Leu et al ${ }^{22}$ in his meta-analysis has suggested that perioperative administration of dexmedetomidine in adult cardiac surgery might be beneficial in reducing the incidence of AKI, opening doors to further studies.

The well-timed initiation of CRRT ${ }^{23,24}$ has been proven to be an effective modality to treat acute kidney injuries, with its use increasing over time. It has shown to decrease morbidity and improve survival.

\section{CONCLUSION}

Postoperative renal dysfunction is a harbinger of poor prognosis after open heart surgery. The acuteness of symptoms, gravity of cardiovascular disease and associated factors related to the CPB put the kidneys at extreme risk. The frequency of renal dysfunction resulting as cause of open heart surgery is $30.3 \%$ which is quite high. It is emphasized to establish early diagnosis in order to institute corrective measures offering 
adequate hydration, and avoidance of potentially toxic metabolites and drugs with multi-disciplinary approach including cardiac surgeon, cardiologist, anesthetist, nephrologist, intensivist and nurses. The strategy need to first define renal dysfunction and then to design a uniform pathway to avoid morbidities to prevent development of full-fledged renal failure in the narrow time frame.

\section{Grant Support \& Financial Disclosures: None.}

\section{REFERENCES}

1. Regner KR. Epidemiology of acute kidney injury after cardiac surgery: an update. J Organ Dysfunction. 2007;3(4):232239. doi: $10.14797 /$ mdcj-8-3-31

2. Zakeri R, Freemantle N, Barnett V, Lipkin GW, Bonser RS, Graham TR, et al. Relation between mild renal dysfunction and outcomes after coronary artery bypass grafting. Circulation. 2005;112(9_Supplement):I-270. doi: 10.1007/s11748-013-0306-5

3. Hobson CE, Yavas S, Segal MS, Schold JD, Tribble CG, Layon AJ, et al. Clinical Perspective. Circulation. 2009;119(18):2444-2453.

4. Lagny MG, Jouret F, Koch JN, Blaffart F, Donneau AF, Albert $\mathrm{A}$, et al. Incidence and outcomes of acute kidney injury after cardiac surgery using either criteria of the RIFLE classification. BMC Nephrol. 2015;16(1):76. doi: 10.1186/s12882-015-0066-9

5. Boldt J, Brenner T, Lehmann A, Suttner SW, Kumle B, Isgro F. Is kidney function altered by the duration of cardiopulmonary bypass? Ann Thorac Surg. 2003;75(3):906-912. doi: 10.1016/j.athoracsur.2011.04.123

6. Sreeram GM, Grocott HP, White WD, Newman MF, Stafford-Smith M. Transcranial Doppler emboli count predicts rise in creatinine after coronary artery bypass graft surgery. J Cardiothor Vascul Anesth. 2004;18(5):548-551. doi: 10.1053/j.jvca.2004.07.010

7. Duque-Sosa P, Martínez-Urbistondo D, Echarri G, Callejas R, Iribarren MJ, Rabago G, et al, Spanish group of renal dysfunction in cardiac surgery (GEDRCC-2). Perioperative hemoglobin area under the curve is an independent predictor of renal failure after cardiac surgery. Results from a Spanish multicenter retrospective cohort study. PLoS One. 2017;12(2):e0172021.

8. Benedetto U, Sciarretta S, Roscitano A, Fiorani B, Refice S, Angeloni E, et al. Preoperative angiotensin-converting enzyme inhibitors and acute kidney injury after coronary artery bypass grafting. Ann Thorac Surg. 2008;86(4):1160-1165. doi: 10.1016/j.athoracsur.2008.06.018

9. Kashif W, Khawaja A, Yaqub S, Hussain SA. Clinically significant contrast induced acute kidney injury after non-emergent cardiac catheterization--risk factors \& impact on length of hospital stay. J Coll Physicians Surg Pak. 2013;23(12):842-847.

10. Parolari A, Pesce LL, Pacini D, Mazzanti V, Salis S, Sciacovelli C, et al. Research Group on Cardiac Surgery Outcomes. Risk factors for perioperative acute kidney injury after adult cardiac surgery: role of perioperative management. Ann Thorac Surg 2012;93(2):584-591. doi:10.1016/j.athoracsur.2011.09.073

11. Yeo KK, Li Z, Yeun JY, Amsterdam E. Severity of chronic kidney disease as a risk factor for operative mortality in nonemergent patients in the California coronary artery bypass graft surgery outcomes reporting program. Am J Cardiol. 2008;101(9):1269-1274.

12. Ramakrishna MN, Hegde VD, Kumarswamy GN, Gupta R, Moola NS, Suresh KP. Impact of preoperative mild renal dysfunction on short term outcome in isolated coronary artery bypass (CABG) patients. Indian J Crit Care Med. 2008;12(4):158-162. doi: 10.4103/0972-5229.45075
13. Bellomo R, Ronco C, Kellum JA, Mehta RL, Palevsky P. Acute renal failure-definition, outcome measures, animal models, fluid therapy and information technology needs: The Second International Consensus Conference of the Acute Dialysis Quality Initiative (ADQI) Group. Crit Care. 2004;8(4):R204. doi: 10.1186/cc2872

14. Mehta RL, Kellum JA, Shah SV, Molitoris BA, Ronco C, Warnock DG, et al. Acute Kidney Injury Network: report of an initiative to improve outcomes in acute kidney injury. Crit Care. 2007;11(2):R31. doi: 10.1186/cc5713

15. Khwaja A. KDIGO clinical practice guidelines for acute kidney injury. Nephron Clin Pract. 2012;120(4):c179-c184.

16. Provenchere S, Plantefeve G, Hufnagel G, Vicaut E, de Vaumas C, Lecharny JB, et al. Renal dysfunction after cardiac surgery with normothermic cardiopulmonary bypass: incidence, risk factors, and effect on clinical outcome. Anesth Analgesia. 2003;96(5):1258-1264. doi: 10.2215/CJN.07830814

17. Lassnigg A, Schmidlin D, Mouhieddine M, Bachmann LM, Druml W, Bauer P, et al. Minimal changes of serum creatinine predict prognosis in patients after cardiothoracic surgery: A prospective cohort study. J Am Soc Nephrol. 2004;15(6):15971605. doi: 10.1097/01.asn.0000130340.93930.dd

18. Hedley AJ, Roberts MA, Hayward PA, Shaw M, Matalanis $\mathrm{G}$, Buxton BF, et al. Impact of chronic kidney disease on patient outcome following cardiac surgery. Heart Lung Circ. 2010;19(8):453-459. doi: 10.1016/j.hlc.2010.03.005

19. Simon C, Luciani R, Capuano F, Miceli A, Roscitano A, Tonelli E, et al. Mild and moderate renal dysfunction: impact on short-term outcome. Eur J Cardiothorac Surg. 2007;32(2):286-290. doi: 10.1016/j.ejcts.2007.04.032

20. Fortrie G, de Geus HR, Betjes MG. The aftermath of acute kidney injury: a narrative review of long-term mortality and renal function. Crit Care. 2019;23(1):24.

21. Pickkers P, Mehta RL, Murray PT, Joannidis M, Molitoris BA, Kellum JA, et al. Effect of human recombinant alkaline phosphatase on 7-day creatinine clearance in patients with sepsis-associated acute kidney injury: a randomized clinical trial. JAMA. 2018;320(19):1998-2009. doi: 10.1001/ jama.2018.14283

22. Liu Y, Sheng B, Wang S, Lu F, Zhen J, Chen W. Dexmedetomidine prevents acute kidney injury after adult cardiac surgery: a meta-analysis of randomized controlled trials. BMC Anesthesiol. 2018;18(1):7. doi: 10.1186/s12871-018-0472-1

23. Crescenzi G, Torracca L, Pierri MD, Rosica C, Munch C, Capestro F. 'Early' and 'late' timing for renal replacement therapy in acute kidney injury after cardiac surgery: a prospective, interventional, controlled, single-centre trial. Interact Cardiovasc Thorac Surg. 2015;20(5):616-621. doi: 10.1093/icvts/ivv025

24. Zou H, Hong Q, Gaosi XU. Early versus late initiation of renal replacement therapy impacts mortality in patients with acute kidney injury post cardiac surgery: a meta-analysis. Crit Care. 2017;21(1):150. doi: 10.1186/s13054-017-1707-0

\section{Authors' Contribution:}

TAA: Designed and conceived with data collection, analysis and editing.

KT: Helped in statistical analysis, manuscript writing and formal lay out.

AS: Helped in data collection and biostatistics SF: Study team supervisor, proof reading and final approval. 